\title{
Diálogos históricos e historiográficos: séculos XIX e XX
}

\author{
Historical and historiographical dialogues: $19 \mathrm{t}^{\mathrm{h}}$ and $20^{\text {th }}$ centuries
}

\author{
Marcia Naxara \\ mrnaxara@uol.com.br \\ Professora assistente \\ Universidade Estadual Paulista Júlio de Mesquita Filho - Franca \\ Departamento de História \\ Rua Fernão Dias, 8/72 \\ 05427-000 - São Paulo - SP \\ Brasil
}

\begin{abstract}
Resumo
Procuro justapor as perspectivas de dois autores que, com pouco mais de um século de distância, apresentaram distintas preocupações quanto ao conhecimento do Brasil e a escrita de sua história: Henrique de Beaurepaire-Rohan (1812-1894) e Manoel Luiz Salgado Guimarães (1952-2010). Para o primeiro, conhecer o país, seu território e sua formação era necessário à construção da nacionalidade, considerando a relação entre o passado, o estudo do presente e as perspectivas de futuro então abertas à jovem nação. Para o segundo, fundamental era o estudo dos procedimentos historiográficos e o acompanhamento das discussões que envolveram a escrita da história de um "ponto de vista nacional" no Brasil do século XIX. Trata-se, portanto, de um exercício de aproximação (e afastamento) entre os objetivos do historiador de hoje, dedicado ao estudo de textos fundacionais em circulação no Instituto Histórico e Geográfico Brasileiro (IHGB); e os

11 propósitos do historiador oitocentista, revelando, de certo modo, os caminhos do conhecimento histórico entre nós.
\end{abstract}

\section{Palavras-chave}

Historiografia; Manoel Luiz Salgado Guimarães; Henrique de Beaurepaire-Rohan.

\begin{abstract}
In this paper, I try to juxtapose the historiographical perspectives of two authors - Henrique de Beaurepaire-Rohan (1812-1894) and Manoel Luiz Salgado Guimarães (1952-2010). In spite of being intellectuals whose lives were separated by more than a century, both had strong interests on knowledge about the writing Brazil's history. For Beaurepaire-Rohan, cultivating knowledge of Brazil's geographical and historical constitution was needed for the larger task of constructing the nation. Guimarães, on his side, used to dedicate special attention to the study of historiographical procedures and to understanding the debates around the issue of how to write history from a "national point of view" in nineteenth-century Brazil. The paper is thus an exercise in approaching and distancing the aims of today's historians to/from those of their nineteenth-century counterparts.
\end{abstract}

Keywords

Historiography; Manoel Luiz Salgado Guimarães; Henrique de Beaurepaire-Rohan.

Recebido em: 26/6/2013

Aprovado em: 17/10/2013 
Habitamos um país ainda pouco conhecido do estrangeiro, e que nós mesmos mal conhecemos. É dever nosso estudá-lo com a dedicação que inspira o patriotismo, e revelar ao mundo seus preciosos dotes. Com a simples e verídica exposição dos factos destruiremos certos preconceitos nascidos da ignorância, e que a má fé de escritores sem consciência tem propalado em nosso detrimento (BEAUREPAIRE-ROHAN 1877/2010, p. 159).

A presente coletânea oferece um conjunto de textos produzidos no Brasil ao longo do século XIX, apresentando os modelos de escrita adequados à narrativa do passado necessário às demandas do presente. Tais demandas eram articuladas ao projeto de afirmação do Estado nacional sob a forma monárquica no Brasil. Publicados nas páginas da Revista do Instituto Histórico e Geográfico Brasileiro, importante espaço de formulação de projetos para a nação em construção, muitos deles não foram reeditados. O conjunto aqui apresentado nos permite visualizar uma interessante disputa em torno do passado desejado para a nação brasileira e das formas necessárias para uma adequada escrita da história nacional (GUIMARÃES 2010, p. 10).

O reconhecimento de diferentes aspectos que possibilitam pensar o Brasil, incluindo a consideração do contorno geográfico que o conforma como país/ paisagem e contém suas inúmeras outras paisagens identitárias - litorâneas e interiores -, constituiu elemento importante em movimentos realizados por intelectuais brasileiros do século XIX em seus projetos de conhecimento do país e de formulação de sua história, ou de suas histórias, bem como dos diferentes modos pelos quais se daria a conhecer e reconhecer a nacionalidade. Interesses que tinham por base tanto o mapeamento do solo em seus inúmeros acidentes geográficos, como a avaliação de potencialidades que poderiam ser colocadas no horizonte do novo país/nação. Ou seja, a idealização e visualização de possibilidades para a realização de projetos vinculava-se, ao menos em parte, à cartografia e ao mapeamento dos recursos físicos e humanos do passado e do presente, tendo em vista a construção sistemática de saberes que constituíssem memória e possibilitassem perspectivar e projetar o futuro, a partir do conhecimento do passado e da compreensão do presente em linha de continuidade.

Um segundo movimento, que ganhou consistência nas últimas décadas do século XX, pode ser reconhecido no interesse crescente pela reflexão e exploração dos mecanismos de memória e escrita - ou seja, de narrativas historiográficas com a potência de se inscreverem na memória coletiva -, não somente da história do Brasil em suas diferentes formas, mas dos caminhos percorridos para a sua consecução, ou seja, da sua historiografia. Em ambos podemos reconhecer, ainda que com perspectivas bastante diferenciadas, um interesse comum pela história de forma geral e pela história do Brasil, em específico.

Procuro colocar em diálogo, no sentido acima enunciado, reflexões que confluem no duplo investimento de ampliação do conhecimento: sobre o Brasil e sobre a escrita de sua história. Separadas por aproximadamente um século e, me parece, podendo ser aproximadas pela preocupação que lhes é central no que diz respeito à história. O texto de Henrique de Beaurepaire-Rohan (1812-1894), Estudos acerca da organização da carta geográfica e da história física e politica do Brasil, 
publicado em 1877, ${ }^{1}$ recentemente reproduzido como documento, com comentários esclarecedores, no volume Livro de fontes de historiografia brasileira, organizado por Manoel Luiz Salgado Guimarães (1952-2010), com publicação póstuma em 2010,² além de colocações centrais do autor sobre a área de estudos historiográficos.

Caminhos reflexivos que, na sua historicidade, somam e se inserem no fazer contínuo da história e da sua escrita em processo de permanente revisão. Colaboram para a reinscrição do conhecimento em formas de representar e reinventar o passado (RICOEUR 2000/2007, p. 9-39). Recortam e rearranjam fragmentos, ao "recopiar, transcrever ou fotografar", de forma a construir e atribuir lugares e significados (CERTEAU 1975/2002, p. 81), em operações historiográficas que vinculam, continuamente, presente e passado.

Penso que podemos tomar os escritos de ambos como projetos - Beaurepaire-Rohan e Manoel Salgado Guimarães - que guardam relação, em que pese o seu distanciamento no tempo e nos procedimentos que os informam. Têm em comum a preocupação e proposta de elaboração e ampliação do conhecimento sobre o Brasil: no primeiro caso, Beaurepaire-Rohan tomava em consideração o vasto território da nova nação que então se formava, na perspectiva de formulação de uma "Carta Geral do Império", ampla, que ambicionava constituir um abrangente tratado sobre o país, para o que propunha um esboço em forma de projeto; no segundo, Guimarães tencionava a reunião e divulgação, em leitura crítica, de reflexões produzidas sobre o Brasil no século XIX, ou seja, de documentos que alimentaram os caminhos - na ocasião iniciais - de formulação de uma história para o Brasil, num momento em 116 que se ambicionava a definição de modelos e métodos fundantes para a escrita $\mathrm{da}(\mathrm{s})$ história(s), que possibilitasse(m) conformar a nacionalidade brasileira e uma memória coletiva nacional. Alguns bastante conhecidos hoje; outros, retomados por Guimarães em seus estudos. Do volume constam nove documentos, redigidos por membros do IHGB - Instituto Histórico e Geográfico Brasileiro, entre 1839 e 1894, numa proposta de leitura do passado que, segundo Guimarães, possibilita acompanhar o debate que então se travava em termos das proposições para a conformação da história, por meio de suas memórias, lembranças e articulação dos argumentos que garantiria a coerência do todo. Vale a pena enumerar datas e títulos dos textos que foram apresentados no espaço criado pelo IHGB, como sabemos, sob os auspícios do Imperador Pedro II, de forma a conferir visualidade à centralidade da nação no bojo das preocupações que movimentaram os homens naquele momento:

\begin{tabular}{|c|c|}
\hline 1839 & $\begin{array}{c}\text { Discurso no ato de estatuir-se o Instituto Histórico e Geográfico Brasileiro } \\
\text { Januário da Cunha Barbosa }\end{array}$ \\
\hline 1841 & $\begin{array}{c}\text { Quais os meios de que se deve lançar mão para obter o maior número possível de } \\
\text { documentos relativos à história e geografia do Brasil? } \\
\text { Rodrigo de Souza da Silva Pontes }\end{array}$ \\
\hline
\end{tabular}

\footnotetext{
${ }^{1}$ Texto publicado em 1877, pela Tipografia Nacional e, na forma de artigo na Revista do Instituto Politécnico Brasileiro, vol. 8, p. 1-36 (GUIMARÃES 2010, p. 188).

2 O presente volume constituiu parte de projeto amplo na perspectiva dos estudos de Guimarães, que visavam a ampliação das reflexões de ordem historiográfica no presente e do conhecimento sobre a historiografia do século XIX, como demonstra o conjunto de sua produção.
} 


\begin{tabular}{|c|c|}
\hline 1843 & $\begin{array}{l}\text { Como se deve escrever a história do Brasil } \\
\text { Karl Friederich Phillipe (sic) von Martius / Carlos Frederico Ph. de Martius }\end{array}$ \\
\hline 1843 & $\begin{array}{c}\text { Memória sobre o melhor plano de se escrever a história antiga e moderna do Brasil. } \\
\text { Henrique Julio de Walenstein }\end{array}$ \\
\hline 1847 & $\begin{array}{c}\text { Parecer acerca das memórias sobre o modo pelo qual se deve escrever a } \\
\text { história do Brasil } \\
\text { Comissão: Francisco Freyre Allemão; Monsenhor Joaquim da Silveira; Dr. Thomaz } \\
\text { Gomes dos Santos }\end{array}$ \\
\hline 1863 & $\begin{array}{l}\text { Dissertação acerca do sistema de se escrever a história antiga e moderna do Império } \\
\text { do Brasil } \\
\text { Raimundo José da Cunha Matos }\end{array}$ \\
\hline 1877 & $\begin{array}{c}\text { Estudos acerca da organização da carta geográfica e da história física e política do } \\
\text { Brasil } \\
\text { Henrique de Beaurepaire-Rohan }\end{array}$ \\
\hline 1884 & $\begin{array}{l}\text { Programa de história do Brasil } \\
\text { João Capistrano de Abreu }\end{array}$ \\
\hline 1894 & $\begin{array}{l}\text { Indicações sobre a história nacional } \\
\text { Tristão de Alencar Araripe }\end{array}$ \\
\hline
\end{tabular}

Títulos que nos mostram a preocupação com o conhecimento do passado e do presente - história e geografia do Brasil; história do Brasil; história antiga e moderna do Brasil; história física e política do Brasil; história nacional - com duração no tempo quanto à compreensão do que fosse a história do Brasil em sua configuração nacional, capaz de expressar sua unidade: espacial, material, histórica e cultural - também visível nas propostas: quais os meios; como se deve; o melhor plano; organização; programa; indicações sobre. Enfim, procura dos melhores meios e da melhor forma para o esforço de síntese que proporcionasse a apreensão e compreensão do país/nação, conferindo-Ihe historicidade e presença. Revelam sintonia com relação ao domínio das sensibilidades - em que as questões relacionadas à con-formação da nação passavam pela configuração geográfica, que envia a uma cartografia e a delineamentos precisos, importantes para o desencadeamento dos sentidos caros à constituição e elaboração do Brasil - pelos sentimentos de pertencimento a um lugar, uma região, um país, uma nação - de nascimento ou adoção. E, também, à construção de uma história, capaz de fornecer, por sua vez, sentidos de continuidade e vínculo entre passado, presente e futuro.

Em 2007, Manoel Salgado Guimarães havia publicado uma fina análise dos textos de Januário da Cunha Barbosa (1780-1846), Rodrigo de Souza da Silva Pontes (1799-1855) e Raimundo José da Cunha Matos (17761839), ${ }^{3}$ antecedida das considerações que impulsionavam seus estudos e a

\footnotetext{
3 Memória lida em 1838 e publicada, postumamente, em 1863 (GUIMARÃES 2007, p. 114).
} 
escolha desses três autores como fundantes de uma historiografia que se pretendia nacional e que, ao constatar o desconhecimento do passado do país, procurava definir modelos, localizar lacunas e construir os indicativos necessários à construção do passado e do presente, promovendo a institucionalização da história como conhecimento. Análises que se somavam aos seus trabalhos anteriores como o artigo "Nação e civilização nos trópicos: o Instituto Histórico e Geográfico Brasileiro e o projeto de uma história nacional", de 1988, que antecedeu a tradução, também póstuma, de seu doutorado Historiografia e nação no Brasil: 1838-1857, de 1987, publicado em 2011. O conjunto de seus textos - outros poderiam ser somados contribui para a visualização de como Guimarães procurou conformar o campo historiográfico do Brasil no século XIX e, simultaneamente, refletir sobre o crescente interesse pela historiografia como área de estudos, já não tão recente, entre os historiadores.

Textos e escolhas que aproximam de forma indelével espaço, natureza, gentes, tempos e temporalidades na expectativa de conformar saberes históricos e historiográficos - que possibilitam pensar a história. Projetos ambiciosos - de constituição e construção do conhecimento.

\section{História e escrita da história}

Beaurepaire-Rohan, como Presidente da Comissão da Carta Geral do Império, dirige-se ao Ministro e Secretario de Estado dos Negócios da

118 Agricultura, Comércio e Obras Públicas, em 1877, para apresentar a Memória [monografia] - "Organização da Carta Geográfica e da História física e politica do Brasil". Cabe lembrar que ele era membro da SAIN - Sociedade Amigos da Indústria Nacional (1828), locus de fundação, em 1838, do IHGB - Instituto Histórico e Geográfico Brasileiro, além de ter perfilado na SCI - Sociedade Central de Imigração, fundada em 1883. Entre outros escritos, apresentou ao mesmo Ministério da Agricultura, no ano seguinte, a Memória [monografia] "O futuro da grande lavoura e da grande propriedade no Brasil" (Congresso Agrícola 1878). O conjunto de seus escritos, a meu ver, possibilita visualizar um Projeto de Brasil, a partir da preocupação com a delimitação de seus diferentes espaços, contornos e acidentes geográficos - meio físico; da sua ocupação pelo trabalho e pela produção de novos conhecimentos possibilitados pelo desenvolvimento da ciência de então, levando a uma crescente percepção dos espaços que conformavam o Brasil como território nacional de que decorria a necessidade, pelos homens da época, de sua afirmação e ocupação como tal (GUIMARÃES 2010, p. 16).

Soma, nas palavras de Guimarães, com o movimento diverso e diferenciado de "produção de sentido e significado para o passado" (GUIMARÃES 2010, p. 9), constituindo um dos elementos no cenário de disputas e tensões que foram conformando e afirmando o Brasil como país e nação e a monarquia como regime político. Colaborador no esforço de procura e produção de documentos e da organização de evidências para o estabelecimento de um conhecimento confiável sobre o Brasil - documentos 
fundadores, com que se buscava alicerçar a sustentação do todo unitário, simultaneamente reconhecido em sua unidade e em suas diferenças. Recuperação importante, na perspectiva de conhecer os elementos do debate e as formas que foi tomando em processos de afirmação do passado e, por consequência, da nacionalidade.

Beaurepaire-Rohan, logo na "Parte Primeira - Da Carta Geográfica" - afirma a intenção de "bem representar o Brasil, tanto gráfica, como descritivamente" (BEAUREPAIRE-ROHAN 1877/2010, p. 159). Por comparação com a França, aponta as dificuldades técnicas para a aplicação da geodesia para a confecção da Carta do Império, tendo em vista o fato do Brasil ser inculto e desconhecido na maior parte de sua grande extensão. Afirma a necessidade da reunião de documentos que sejam dignos de confiança referindo-se à Carta que havia sido preparada para a Exposição Nacional de 1875 e para a Internacional da Filadélfia de 1876 - elaborada a partir de documentos "autênticos", fornecidos pelo Sr. Barão da Ponte-Ribeiro" (BEAUREPAIRE-ROHAN 1877/2010, p. 161) - com ênfase na perspectiva e necessidade da reunião de documentos que pudessem dizer do passado e do presente do Brasil. Nesse sentido, indica como necessário o envio de modelo a todas as províncias, com procedimentos a serem observados, tendo em vista a coleta de novas informações, bem como a correção de possíveis enganos encontrados naquelas já existentes, de forma a crescentemente aperfeiçoar o conhecimento e alcançar a Carta Geral do Império, ainda que, dadas as limitações técnicas, não fosse possível construí-la com precisão.

Em publicação recente, de 2012 - A cartografia impressa do Brasil -, Max Justo Guedes reuniu o que considera "os 100 mapas mais influentes" do Brasil entre os anos de 1506 e 1922. Nele consta, além da Carta de 1875, uma segunda, também elaborada sob a Presidência do General Henrique de Beaurepaire-Rohan, datada de 1883. Guedes observa que a primeira delas abrange "parte dos países com os quais [o Brasil] faz fronteira", incluindo "trecho do Oceano Pacífico", além de "representação de relevo e localização de grupos indígenas" (GUEDES 2012, p. 85). A segunda contém "a designação das ferrovias, colônias, engenhos centrais, linhas telegráficas e de navegação a vapor" (GUEDES 2012, p. 87), também elaborada por solicitação do Ministério da Agricultura, demonstrando o empenho quanto ao esquadrinhamento da terra brasileira e de seus recursos. Os recortes a seguir possibilitam avaliar os resultados do investimento e o nível de detalhe em termos da cartografia brasileira efetivada para o conhecimento do território e de seu potencial. ${ }^{4}$

\footnotetext{
${ }^{4}$ Os mapas podem ser vistos com maior detalhe no volume A cartografia impressa do Brasil - 1506-1922. A partir da delimitação de 100 mapas para a composição do volume, o autor escolheu os mapas impressos tendo em vista sua maior circulação e, portanto, influência na divulgação do conhecimento neles condensados. Na afirmação de Pedro Correa do Lago, foram mapas que "realmente fizeram diferença no conhecimento ampliado do delineamento da costa brasileira e na identificação progressiva dos principais acidentes geográficos do interior" (LAGO 2012, p. 10).
} 


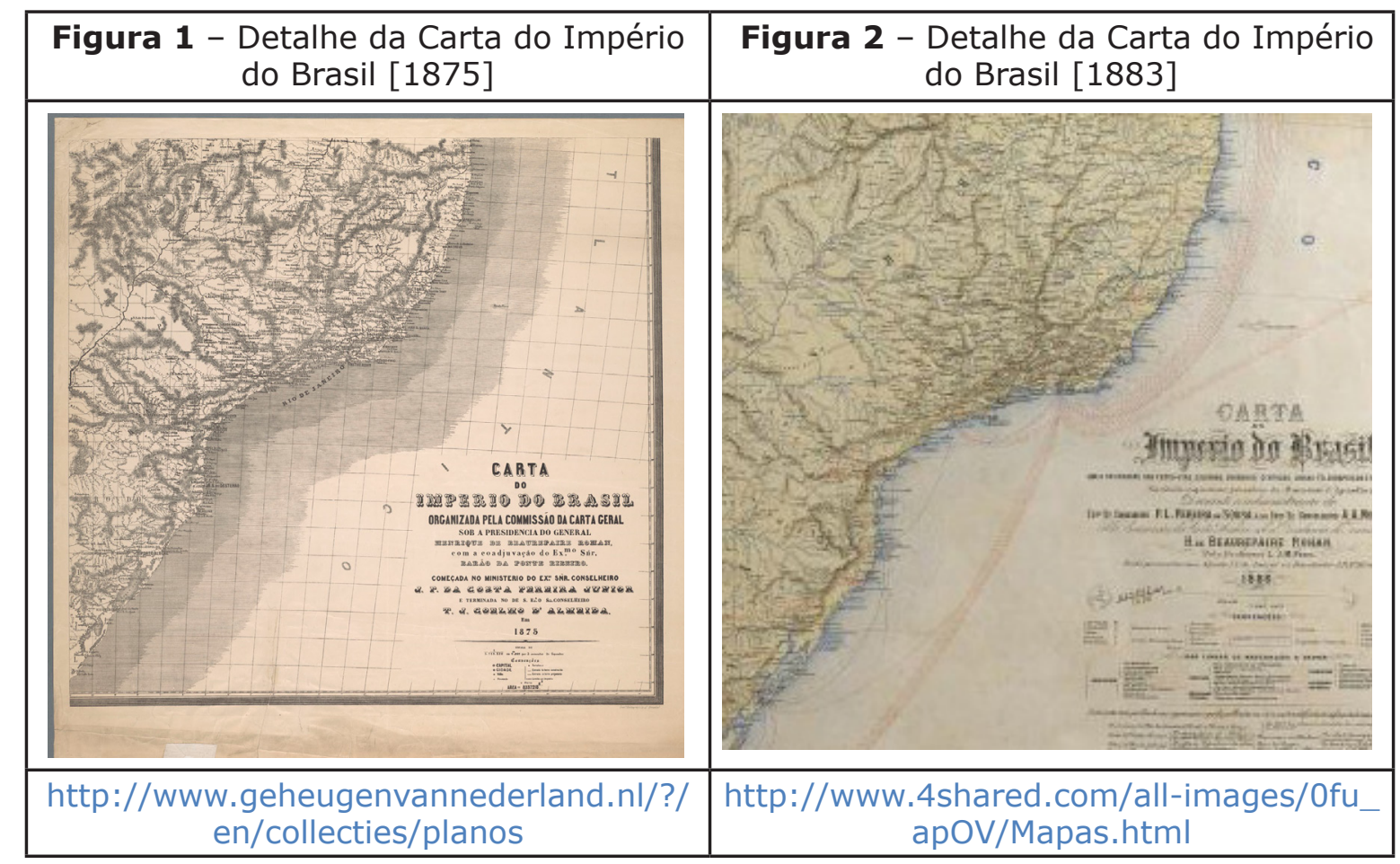

Desse esforço, pode-se concluir, resulta uma busca mais do presente que do passado, pautada pela procura do que se considerava necessário para se perspectivar o futuro: delimitar o Império em termos de sua geografia, descrevêlo e representá-lo graficamente em seus inúmeros detalhes; explicitar suas características por meio de códigos, traçados e dispositivos simbólicos. Reunir elementos para avaliar possibilidades, conferindo organicidade e visualidade a conhecimentos que se encontravam dispersos. Visualidade efetivada pela síntese de conjunto proporcionada pelo mapa, cartografia que desenha e compõe o traçado/contorno da paisagem Brasil, fundamental para definir a nação, alimentar os sentimentos pátrios e estreitar os vínculos com a terra, para uns de nascimento, para outros de adoção: o traçado delineia a costa e sugere as fronteiras interiores por regiões menos conhecidas, realça a malha hídrica e demais acidentes notáveis da sua topografia, destaca o conjunto da natureza e, também, as realizações que resultam de sua ocupação pelos homens: áreas trabalhadas pela agricultura e outras atividades, riquezas naturais, caminhos de ferro que comungam com os rios, os recortes caprichosos de seu imenso litoral. No conjunto, representam imagem que remete, na figuração e na imaginação, para a pátria que se quer nação, no momento de tais investimentos. Entre outros conhecimentos, contribuiriam para mobilizar sentimentos que vinculam a paisagem em seus inúmeros detalhes ao país e nação a que se procura dar visibilidade pela cartografia. Imagens que se formam a partir da vinculação pátria, país e paisagem, a que a Carta Geral do Império confere unidade, suscitando o que Catroga (CATROGA 2008) denominou "sentimentos quentes", tendo em vista a mobilização de afetos pátrios, de forma que o Brasil - com seu imenso e diferenciado território - torna-se perceptível pela construção visível do contorno geográfico que lhe dá concretude e possibilita que a imaginação seja lançada longe em termos de representações e, mesmo, da 
dicotomia que acompanha o "conhecimento e exploração de seu território, marcado de forma forte pela litoraneidade, por uma ocupação que se fez pelas beiradas, deixando uma enorme quantidade de terras interiores por conhecer e dominar: naturezas e povos selvagens, indígenas, sertões" (NAXARA 2013).

As indicações dos trabalhos que informaram e possibilitaram a realização da Carta Geral do Império de 1875 foram publicadas pelo Barão da Ponte Ribeiro, que reuniu, também para a Exposição Nacional de 1875, significativo número de "trabalhos históricos, geográficos e hidrográficos", considerando a conveniência de "oferecer ao publico uma exposição, ainda que resumida, desses trabalhos". Escolheu fazê-lo utilizando a ordem cronológica, tendo por ponto de partida o extremo setentrional do Império - "Planta do rio Oiapoque até o Forte de S. Luiz, [...], que em 1794 levantou...", informando possuir a "planta e o respectivo relatório". Dá continuidade com relatos sucintos e claros de cada um dos documentos e, desta forma, indica o objetivo da soma de informações que possibilitaram a elaboração da Carta, ainda que com deficiências: da "Parte Setentrional" (1-85 documentos), segue para a "Parte Ocidental" (86-128), "Parte Meridional" (129-173), "Parte Oriental" (174-289) e "Parte Central" (290-306), a que acrescentou as "Cartas que representam território compreendido em mais de uma das cinco precedentes divisões" (307-321) e, ainda, "Cartas que compreendem todo o Brasil" (322-330) (RIBEIRO 1876). Esclarece, ao final, que a existência de tantos mapas antigos no Arquivo Militar se devia à notícia, que chegara à Corte em 1811, de "estar em Santarém o General Massena com um exercito destinado a consumar a conquista de Portugal", o que levou à emissão de ordens aos "Governadores do Reino para remeterem todos os Mapas Geográficos, planos topográficos, e plantas de fortalezas, e as respectivas memorias, que estivessem nos Arquivos de Lisboa, afim de evitar que caíssem no poder dos Franceses" (RIBEIRO 1876, p. 90). A quantidade de documentos por região só vem comprovar o enorme desconhecimento do Brasil interior, ainda que, ao olhar, impressionem pelo traçado - firme ao longo do litoral e somente sugerido nas fronteiras interiores - e pelos detalhes.

Figura 3 - Detalhe da Carta do Império do Brasil [1883]

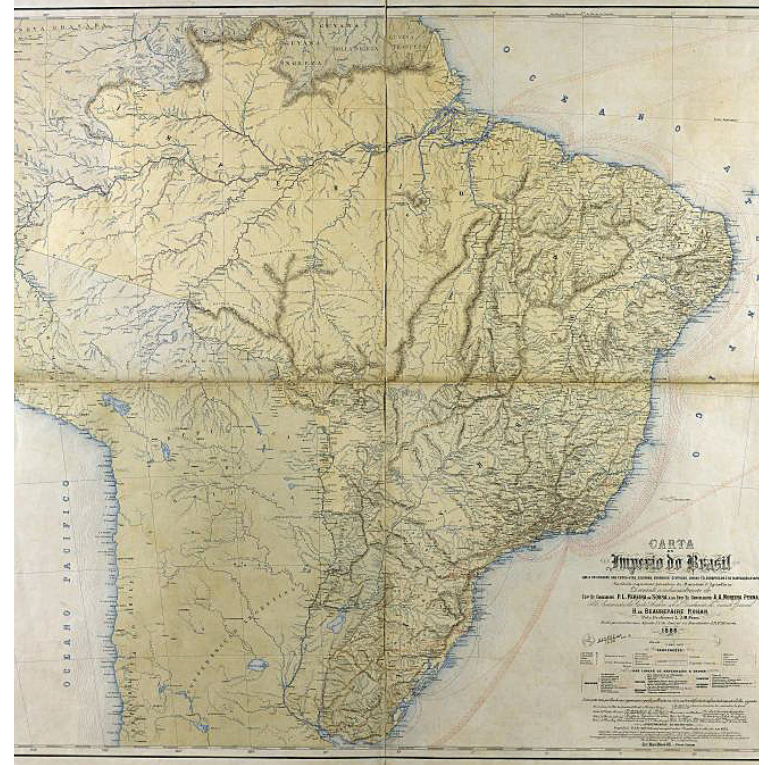


Para dar continuidade à perspectiva do projeto que propõe, na "Parte Segunda - Da História Física e Política do Brasil", Beaurepaire-Rohan procede a uma seleção historiográfica, nomeando quatro autores no que afirmou constituir, como espectro de escolha, "numerosa plêiade de historiadores e geógrafos": Pero Vaz de Caminha, Pero de Magalhães Gandavo, Gabriel Soares de Souza e Manoel Ayres do Casal. Parte da Carta de Caminha como "primeira página da história do Brasil", que teve a sorte de "ter tido um historiador no mesmo dia de sua descoberta" (BEAUREPAIRE-ROHAN 1877/2010, p. 167-168), ${ }^{5}$ com as primeiras informações das terras e das gentes.

Na sequência indica a publicação de 1576, em Lisboa, da História da Província de Santa Cruz, por Magalhães Gandavo. Na sua afirmação, em que pesem as notícias que o autor traz sobre a terra, demonstrando o interesse por melhor conhecê-la, os indicativos de sua localização constituem "a prova à mais peremptória da ignorância naqueles tempos sobre a verdadeira posição e extensão do Brasil", apresentado como alcançando "as altíssimas serras dos Andes e fraldas do Peru" a ocidente. Soares de Souza, em 1587, no Roteiro geral com largas informações de toda a costa do Brasil, teria cometido os mesmos erros de Gandavo quanto aos limites sul e norte; teria, no entanto, se "acautelado" no que diz respeito às terras a ocidente, sobre as quais, de acordo com BeaurepaireRohan, guardou silêncio. Elogia e assinala a importância da "minuciosa descrição" que o autor faz da costa oriental, pelo reconhecimento de "baias, enseadas, ancoradouros e rios". Reconhece em ambos, Gandavo e Soares de Souza 122 como qualidade - as referências aos recursos naturais e à população aborígene (BEAUREPAIRE-ROHAN 1877/2010, p. 170-171). Os indígenas aparecem como preocupação quanto à sua localização no mapeamento geográfico e, também como objeto de estudo nas menções realizadas pelos primeiros historiadores das coisas do Brasil. Cabe lembrar que o Imperador havia encomendado ao General Couto de Magalhães, para a mesma Exposição Universal da Filadélfia, um estudo sobre as populações indígenas, de que resultou $O$ selvagem, texto em que Couto de Magalhães propôs pensar as formas de aproveitamento do selvagem e das terras por eles ocupadas. No conjunto, verifica-se que a população indígena constituía horizonte de preocupação política e intelectual no período: questão que, como analisa Rodrigo Turin, aparecia como "enigma" do ponto de vista da história, de forma que o historiador do Brasil naquele momento precisaria, também, ser etnógrafo, tendo em vista decifrar a possibilidade de uma história indígena, cercada pela "obscuridade". Ou seja, como conferir historicidade e, mesmo, compreender o presente, de grupos étnicos cujo passado permanecia nas sombras, constituía debate em construção no interior do IHGB, sem um juízo definitivo quanto ao fato de que teriam vivido desde sempre "no estado de natureza" em que foram encontrados, ou se constituíam formas "decaídas", "degeneradas"6 de civilizações anteriores (TURIN 2006). De todo modo, não

\footnotetext{
5 Beaurepaire-Rohan chama a atenção para a utilização, por Caminha, do "calendário juliano, que vigorava no seu tempo", de forma que o dia 22 de abril corresponderia, no calendário gregoriano, ao dia 3 de maio (BEAUREPAIRE-ROHAN 1877/2010, p. 169).

${ }^{6}$ Questão que aparece de forma bastante interessante no romance de Martius Frey Apollonio: um romance
} 
teriam tido atenção privilegiada ao longo do século no IHGB e nas páginas de sua Revista, como nos informa o minucioso estudo de Lúcia Guimarães (GUIMARÃES 1995, p. 575-576). À população indígena somava-se o grande número de escravos e seus descendentes, ${ }^{7}$ marcados por silêncio mais gritante ainda, além da dificuldade de enfrentamento do mestiçamento frente a um horizonte modelado pela meta civilizacional europeia.

Beaurepaire-Rohan assinala, já em 1817, a Corografia Brasílica de Ayres do Casal, indicando que, ainda que contivesse muitos e "lamentáveis" erros, entre os quais a ampliação do território brasileiro pela anexação de não pequenas extensões então pertencentes à Coroa espanhola, empenhava-se em "se aproximar o mais possível da verdade". Tem importância marcante. No entanto, não altera o seu juízo quanto à necessidade de construir um conhecimento atualizado sobre o país que havia, até aquele momento, conhecido grande desenvolvimento nos mais variados aspectos e continuava constituindo, em grande parte, um enigma por decifrar (BEAUREPAIRE-ROHAN 1877/2010, p.171-172).

Acrescenta e finaliza pela referência à publicação mais recente à época, do volume O Império do Brasil na Exposição Universal de 1876 em Philadelphia, de 1875, com autoria do Visconde do Bom Retiro. Do seu ponto de vista, a obra supria somente até certo ponto o conhecimento sobre o Brasil, permanecendo a necessidade de uma corografia, ou seja, não havia uma "descrição completa do Brasil, em relação ao seu estado atual". E é nesse sentido que Beaurepaire-Rohan indica sua proposta, a ser encaminhada como um trabalho coletivo, pela aplicação do princípio da "divisão do trabalho", sentido em que se dirige ao Governo, lembrando iniciativa anterior, pelo reconhecimento da necessidade de apoio oficial para a possibilidade de consecução do ambicioso projeto, a ser realizado com "tantos colaboradores quantos forem necessários" (BEAUREPAIRE-ROHAN 1877/2010, p. 172-173).

O "Programa", que então propõe, definia a "Corografia ou História física e política do Brasil" em duas secções, como segue:

A primeira será a descrição geral do Império;

A segunda a do Município da Corte e das Províncias.

A descrição geral do Império terá por base o plano junto, o qual, com as necessárias restrições, servirá também para a descrição do Município da Corte e das Províncias.

Acompanhará a obra uma carta geral do Império

(BEAUREPAIRE-ROHAN 1877/2010, p. 173).

Indica as instruções quanto aos procedimentos que os correspondentes colaboradores deveriam seguir, apontando a necessidade de prazos para a apresentação de trabalhos parciais, bem como os indicativos necessários à finalização dos textos, que seriam aceitos somente após rigorosa revisão, além de prescrever que deveriam ser "escritos em papel almasso [sic] pautado, com

do Brasil, escrito em 1831 e publicado somente na segunda metade do século XX, com tradução publicada no Brasil, pela Brasiliense, em 1992 (NAXARA 1994, p. 251 et seq.).

7 Lucia Paschoal Guimarães assinala que ao longo da segunda metade do século XIX, foram publicados na Revista do IHGB "somente três textos que faziam menção ao elemento negro" (GUIMARÃES 1995, p. 575). 
o numero de ordem na parte inferior da página. O verso da página ficará em branco" (BEAUREPAIRE-ROHAN 1877/2010, p. 174).

No conjunto de prescrições, não há como não chamar a atenção para os indicativos quanto à inclusão de elementos que procurassem cativar o leitor, ou seja, pela ideia de que a história ensinaria o amor da pátria e colaboraria para a produção de vínculos de pertencimento:

Em todas as descrições, até mesmo nas de ordem meramente física, procurarão os colaboradores disfarçar a aridez do assunto por meio de notícias curiosas sobre os acidentes e produções naturais, a paisagem, a historia local e outras circunstâncias que possam interessar o leitor (BEAUREPAIRE-ROHAN 1877/2010, p. 174).

Na sequência, o Plano da Obra, bastante minucioso, tem início pelo "Prólogo" e pela "Descrição geral do Brasil", seguido do "Capitulo I", que, com diversos itens, constituiria a "Descrição física" do país. Na sequência, o "Capitulo II", com a "Descrição política", que teria início com a sua "História", seguida de diferentes itens sobre a população e as atividades econômicas, que incluiriam as riquezas naturais, as atividades extrativas, as artes mecânicas, as belas artes, a literatura e as ciências, não deixando de chamar a atenção o fato de que tais temas aparecem antes de todo o aparato administrativo que lhe segue (BEAUREPAIRE-ROHAN 1877/2010, p. 175-187).

Projeto abrangente que, como vimos, perfilou com outros produzidos ao longo do século XIX, na perspectiva de pensar o Brasil e reunir informações verdadeiras e confiáveis que, sistematizadas, teriam a abrangência indicada no detalhado plano da obra. Tanto o país como o seu passado ganhariam forma e visibilidade no presente: imagens e textos; modos de interpretação que, num conjunto de contribuições e não sem debate e confronto, como afirma Manoel Salgado Guimarães para nomeá-los "textos de fundação", constituiriam uma "forma peculiar de escrita, a escrita da história do ponto de vista nacional" e, também, da emergência do historiador no mundo das letras (GUIMARÃES 2012, p. 12). Textos que encontraram espaço de existência e debate no IHGB e divulgação por meio de sua revista, representando investimentos historiográficos que buscaram o estabelecimento de uma cronologia com sentido - fundante para a demarcação da existência da nação e da nacionalidade - ou seja, a construção da cronologia de uma fundação nacional.

Esforço de aprofundamento com relação à construção de conhecimentos sobre o Brasil que, sabemos, ultrapassou os limites do IHGB, tendo-se pautado não somente pela reunião de saberes técnicos e científicos, mas pelo cruzamento entre "razão e sensibilidade, objetividade e subjetividade" não só no desvendamento, como na criação de representações e imagens do mundo natural, das sociedades e da sua interação. Posicionamento romântico, marcado por sensibilidades e intuições "que alimentaram a construção de representações que incorporaram, em maior ou menor grau, a imaginação" (NAXARA 2004, p. 79), agudizando a consciência histórica, ou seja, a percepção de que a civilização era resultado do tempo, ou seja, materializava-se na história. Perspectiva alimentada pelos contrastes marcantes 
da terra brasileira, na perspectiva dual de suas representações entre os opostos civilização e barbárie e subsequentes formulações de seus litorais e sertões; fatores explicativos importantes para a compreensão de suas singularidades e peculiaridades, em especial dos povos que a habitavam.

Numa visão de conjunto, na perspectiva apontada por Guimarães, bem como no regime de historicidade preponderante no século XIX (GUIMARÃES 2010; HARTOG 2006), tratava-se de assegurar a escrita da história no presente em perspectiva de seu significado para o futuro, tendo em vista a busca de um lugar na história universal para o Brasil, ou seja, um lugar no concerto das nações civilizadas. Não é desconhecida, da parte de Pedro II e daqueles que o cercavam no IHGB, a preocupação com a memória que deixariam para o futuro, ou seja, preocupação com a construção e gestão de uma memória coletiva.

Como indicado de início, a historiografia constitui-se como área de conhecimento interessada na produção não só de saberes em história, mas também na reflexão sobre o trabalho e procedimentos do historiador. Perspectiva que foi central à escolha dos textos que compõem a coletânea, tendo em vista a intenção de Guimarães de recuperar os elementos que estavam em questão no decorrer do século XIX, alimentando o desejo de elaboração de uma história nacional, no caso, para o Brasil. Momento, compartilhado no Ocidente, de escrita das variadas histórias nacionais, que buscaram os caracteres identitários capazes de definir as especificidades e as formas de compreensão e entendimento diferenciado de cada país no concerto das nações. No caso do Brasil, a definição do início e dos eventos que the deram continuidade, marcando sua individualidade e expressão como nação valendo-se da escrita de sua história. Como lembram Paulo Knauss e Temístocles Cezar a partir de Ricoeur, "a origem é mítica e o começo é histórico" (KNAUSS; CEZAR 2011, p. 11). Ambos, início e continuidade, me parece, ganham existência a partir de um lugar: um território, um país, um delineamento, inúmeras paisagens. Várias as interpretações e formas de ver e dimensionar o espaço que se constitui país/ paisagem com seus inúmeros outros espaços e paisagens interiores. Diferentes relações que se instituem no tempo, criando vínculos, embora sempre transitórios - ainda que com duração e razoável estabilidade -, entre presente e passado, por olhares que se materializam em diferentes suportes e configurações, que tocam não somente a consciência, como a sensibilidade, pela coesão de sentimentos que convergem para a constituição da nacionalidade. Pertencimento que coloca, de forma forte, a relação meio natural e meio social (NAXARA 2013).

O século XIX como século da história (GUIMARÃES 2002, p. 184), a que se poderia acrescentar, da biologia, ou mesmo das intrínsecas aproximações que podem ser estabelecidas entre os dois campos do conhecimento no que diz respeito às interpretações do mundo, pelo desenvolvimento de caminhos que possibilitassem perscrutar o passado - com método - produzindo explicações e entendimentos decorrentes do movimento temporal. Movimento que, por sua vez, têm existência na história e, por seu lado, mobiliza "interesses políticos e de conhecimento numa rede complexa em que, se o saber pode significar poder, é também do lugar do poder que se tecem saberes a respeito dos tempos pretéritos" (GUIMARÃES 2002, p. 184), em especial se a composição de uma história nacional 
ocorre a partir de um lugar que conquista e ocupa o direito de fala, mesmo que as falas tenham sido múltiplas e a disputa interior ao IHGB possa ter tido dimensão significativa. Lucia Paschoal Guimarães (GUIMARÃES 1995) acompanhou, extensa e intensamente, a documentação do Instituto, procurando realçar temáticas e debates, exercícios de memória, silenciamento, denegação e esquecimento no desenrolar dos esforços de pesquisa, estabelecimento documental e escrita da história em seu interior: vaidades, interesses, deficiências e debilidades no que diz respeito às possibilidades quanto aos objetivos perseguidos de construção de uma história nacional, continuamente debatido em termos de modelos que pudessem servir à sua consecução.

Conhecer e refletir sobre o desenrolar de tal empreitada foi interesse central ao trabalho de Manoel Salgado Guimarães, no deslindar e acompanhar, colocando presente e passado em relação, os passos iniciais da historiografia praticada no Brasil, referenciada nas formas de conhecimento histórico - teoria e método - vigentes e em construção no século XIX. Interesse especial para com os procedimentos daqueles que iniciaram os estudos históricos, contribuindo, simultaneamente, para a sua constituição como disciplina e ciência e, também, para a pesquisa histórica e definição dos caminhos de formulação de uma história para o Brasil: "Reconstruir o passado que se deseja narrar é a tarefa dessa primeira geração de escritores e literatos que igualmente vão se construindo, por meio da escrita que propõem, como os primeiros historiadores do Brasil" (GUIMARÃES 2010, p. 14-15), em processo praticamente sem fim e, também marcado pelos debates intelectuais e políticos de seu tempo.

A história como parte de uma cultura histórica, na afirmação de Guimarães penso que característica, talvez, ao mundo ocidental - "que supõe inúmeros outros dispositivos coletivos de produção de sentido e significado para o passado" e que se interroga, "de modo sistemático, sobre as diferentes formas de transformar o passado" em objeto de investigação (GUIMARÃES 2010, p. 9). Para o autor é questão que foi adquirindo consistência e relevância no Brasil nas últimas décadas do século $\mathrm{XX}$, podendo-se reconhecer movimentos crescentes de reflexão sobre a própria disciplina, ou seja, sobre o próprio fazer do historiador. Na esteira de Pierre Nora, considera que a "uma percepção cada vez mais acelerada do tempo, a uma velocidade que parece condenar o próprio presente a um esquecimento, os esforços sociais para a 'preservação' do passado assumem cada vez mais sentido" (GUIMARÃES 2007, p. 95-96). A compreensão dessa busca e/ou percepção de sentido do conhecimento o levou, de forma consequente, aos primeiros gestos de construção de uma história nacional para o Brasil, a partir do estudo de textos que, como já apontado, considerava fundantes, uma vez que são articulados, em proveito da formulação de uma escrita coerente para o passado, ou melhor, para a escrita do/sobre o passado, no caso, do Brasil. Afirma valer-se das "sugestões valiosas de Aleida Assmann" para estabelecer "clara distinção entre os textos e restos/vestígios do passado", demarcando as diferentes formas de sua apreensão e, também, o percurso de seu próprio trabalho interessado no estudo das complexas relações que "enredam história e memória", a partir de textos que elaboraram reflexões sobre a história e sobre o momento vivido, na tentativa de 
apreensão do passado e formulação de uma história, de modo que "a produção de conhecimento sobre o passado não deve ser percebida sem suas articulações com o presente em que se realiza" (GUIMARÃES 2007, p. 98-100).

Manoel Salgado Guimarães tem por horizonte, sempre, a tensão constitutiva do trabalho do historiador, "entre uma escrita que busca ordenar, submeter a uma gramática e a uma sintaxe aquilo que por natureza é movediço, sinuoso, tortuoso e corrosivo - as experiências humanas vividas" e a possibilidade da novidade e do inesperado que o trabalho do historiador comporta (GUIMARÃES 2007, p. 15). Aberturas, portanto, para um passado que jamais se cristaliza num conhecimento definitivo, mas que entra na série infinita de reinscrições possíveis.

Retomo o exercício de diálogo dos dois autores em questão - Beaurepaire-Rohan e Manoel Salgado Guimarães -, com realce para o fato de que ambos possuíam, em momentos e situações diversas, propósitos e projetos vislumbrados em termos da produção de conhecimento sobre o Brasil e reflexão sobre o já produzido. Projetos de dimensionamento do já conhecido e das formas que possibilitam pensar o presente em sua relação com o passado. Beaurepaire-Rohan não se pretende historiador, no entanto, consoante ao século XIX em que viveu, escreve para propor perspectivas futuras, realçando a necessidade de ampliação do conhecimento existente sobre a terra brasileira, em sentido amplo, sistêmico e enciclopédico - para o que retomou aspectos e informações, tanto do passado como do presente. Seu olhar, no entanto, dirige-se projetivamente para o futuro, para o que visualiza como possibilidades de efetiva construção da nação. Guimarães, historiador, para quem o "labor historiográfico" é "nossa profissão" e, também, "nossa maneira de estar no mundo" (GUIMARÃES 2007, p. 16), por seu lado, procurou ampliar o conhecimento das formas como se pensou a história, a história das nações e a história do Brasil no século XIX, de forma instigante e a instigar, em ampla conexão com as reflexões sobre o fazer historiográfico, mais do que o conhecimento da história, o fazer do historiador - seu métier - no sentido da indagação frequentemente lembrada de Certeau (que nos faz lembrar Marc Bloch): "O que fabrica o historiador quando 'faz história'?" (CERTEAU 1975/2002, p. 65) realçando, na operação historiográfica o lugar de onde fala o historiador.

Ao encerrar penso que cabe lembrar a aproximação que nos é tão cara, da dimensão e importância da escrita da história, na forma como abordada por Ricoeur (RICOEUR 2000/2007, p. 250-260), em especial quando se tem por foco central uma produção que se faz arquivo de como se pensou a história e o conhecimento não somente da história, mas também de sua trajetória em termos de produção de conhecimento. A escrita que elabora narrativas, para o autor, não somente lhe é central, como está presente em todos os momentos e atividades que compõem a operação historiográfica: do registro no arquivo à produção do texto do historiador. Produção essa que entra na mesma cadeia que vincula passado e presente e, por sua vez, se faz, também, documento. Parece interessante, considerando a trajetória de espaços que inventam paisagens, geográficas e mentais; espaços que são temporalizados e se fazem histórias, encerrar pela símile de Certeau que aproxima os relatos, ou seja, a escrita - não somente da história - , a itinerários que organizam lugares, caminhos e trajetórias (CERTEAU 1990/1994), para pensar a leitura, também, das Cartas Gerais 
do Império que, desenhando cartografias absolutamente necessárias para a orientação pelos caminhos e lugares, uma vez que mapeiam o território de forma a conduzir o leitor por suas veredas - para colocá-la em paralelo com a forma poética que Knauss e Cezar (KNAUSS; CEZAR 2011) utilizaram ao redigir o Prefácio de Historiografia e nação no Brasil, a que deram o título "O historiador e o viajante: itinerário do Rio de Janeiro a Jerusalém", onde realçam, por sua vez, os caminhos percorridos por Manoel Salgado Guimarães, em sua forte e consistente produção sobre o ofício do historiador.

\section{Referências bibliográficas}

4SHARED. http://www.4shared.com/all-images/Ofu_apOV/Mapas.html. [Acesso em 03/06/2013].

BEAUREPAIRE-ROHAN, Henrique de. Estudos acerca da organização da carta geográfica e da história física e política do Brasil. In: GUIMARÃES, Manoel Luiz Salgado. Livro de fontes de historiografia brasileira. Rio de Janeiro: EdUER]; FAPERJ, 2010 [1877], p. 157-191.

. O futuro da grande lavoura e da grande propriedade no Brasil. In: Congresso Agrícola. Coleção de Documentos. Rio de Janeiro: Tipografia Nacional, 1878, p. 242-252.

CATROGA, Fernando. Pátria, Nação, Nacionalismo. In: TORGAL, Luís Reis; PIMENTA, Fernando Tavares; SOUZA, Julião Soares (coord.). Comunidades imaginadas: Nação e nacionalismos em África. Coimbra: Imprensa da Universidade de Coimbra, 2008, p. 9-39.

CERTEAU, Michel de. A escrita da história. $1^{a}$ edição francesa 1975. Trad. Maria de Lourdes Menezes. 2. ed. Rio de Janeiro: Forense Universitária, 2002.

. Relatos de espaço. In: A invenção do cotidiano: 1. artes de fazer. $1^{a}$. edição francesa 1990. Nova edição, estabelecida e apresentada por Luce Giard. Trad. Ephraim Ferreira Alves. Petrópolis: Vozes, 1994, p. 199-217.

GEHEUNGEN VAN NEDERLAND. http://www.geheugenvannederland.nl/?/en/ collecties/planos. [Acesso em 03/06/2013].

GUEDES, Max Justo. A cartografia impressa do Brasil - 1506-1922. Os cem mapas mais influentes. Rio de Janeiro: Capivara, 2012.

GUIMARÃES, Lucia Maria Paschoal. Debaixo da imediata proteção de Sua Majestade Imperial: o Instituto Histórico e Geográfico Brasileiro (1838-1889). R.IHGB, Rio de Janeiro, vol. 156, n. 385, jul./set. 1995, p. 459-613.

GUIMARÃES, Manoel Luiz Salgado. Apresentação. In: Livro de fontes de historiografia brasileira. Rio de Janeiro: EdUERJ; FAPERJ, 2010, p. 7-16. - A disputa pelo passado na cultura histórica oitocentista no Brasil. In: CARVALHO, José Murilo de (org.). Nação e cidadania no Império: novos horizontes. Rio de Janeiro: Civilização Brasileira, 2007, p. 93-122. . Entre amadorismo e profissionalismo: as tensões da prática histórica no 
século XIX. Topoi, Rio de Janeiro, vol. 3, n. 5, dezembro 2002, p. 184-200. (org. ). Estudos sobre a escrita da história. Rio de Janeiro: 7Letras, 2006. Historiografia e nação no Brasil: 1838-1857. Trad. Paulo Knauss e Ina de Mendonça. Rio de Janeiro: EdUERJ; Anpuh, 2011.

- Nação e civilização nos trópicos: o Instituto Histórico e Geográfico Brasileiro e o projeto de uma história nacional. Estudos Históricos Caminhos da historiografia, Rio de Janeiro, vol. 1, n. 1, 1998, p. 5-27.

Prefácio. In: ALBUQUERQUE Jr., Durval Muniz de. História: A arte de inventar o passado. Bauru-SP: Edusc, 2007, p. 15-18.

HARTOG, François. Tempos do mundo, história, escrita da história. In: GUIMARÃES, Manoel Luiz Salgado (org.) Estudos sobre a escrita da história. Rio de Janeiro: 7Letras, 2006, p. 15-25.

KNAUSS, Paulo; CEZAR, Temístocles. Prefácio - O historiador viajante: itinerário do Rio de Janeiro a Jerusalém. In: GUIMARÃES, Manoel Luiz Salgado. Historiografia e nação no Brasil. 1838-1857. Trad. Paulo Knauss e Ina de Mendonça. Rio de Janeiro: Ed.UERJ; Anpuh, 2011, p. 7-21.

LAGO, Pedro Corrêa do. Prefácio - Uma seleção criteriosa e inspirada. In: GUEDES, Max Justo. A cartografia impressa do Brasil - 1506-1922. Os cem mapas mais influentes. Rio de Janeiro: Capivara, 2012, p. 9-11.

NAXARA, Marcia R. C. Brasil: país em paisagens. In: NAXARA, Marcia; CAMILOTTI, Virgínia (orgs.). Conceitos e linguagens: construções identitárias. São Paulo: Intermeios (no prelo).

Cientificismo e sensibilidade romântica: em busca de um sentido explicativo para o Brasil no século XIX. Brasília: Ed.UnB, 2004.

MAGALHÃES, General Couto de. O Selvagem. 4a ed. com "Curso da Língua Geral Tupi". São Paulo-Rio-Recife-Porto Alegre: Cia. Editora Nacional, 1940 [1876].

RIBEIRO, Barão da Ponte. Exposição dos trabalhos históricos, geográficos e hidrográficos que serviram de base à Carta Geral do Império exibida na Exposição Nacional de 1875. Rio de Janeiro: Tipografia Nacional, 1876. Disponível em: http://www2.senado.gov.br/bdsf/handle/id/221761.

RICOEUR, Paul. A memória, a história, o esquecimento. $1^{a}$ edição francesa 2000. Trad. Alain François et.al. Campinas: Ed.Unicamp, 2007.

TURIN, Rodrigo. A "obscura história" indígena. O discurso etnográfico no IHGB (1840-1870). In: GUIMARÃES, Manoel Luiz Salgado (org.) Estudos sobre a escrita da história. Rio de Janeiro: 7Letras, 2006, p. 86-113. 